\title{
METODOLOGIA DE PRODUÇÃO E CARACTERIZAÇÃO DE SCAFFOLDS DE QUITOSANA COM POTENCIAIS APLICAÇṌES MÉDICAS
}

\author{
M. S. Silva*, A. Antunes* \\ *Universidade Federal de Uberlândia, Uberlândia, Brasil \\ e-mail: mardey@ufu.br
}

Resumo: A quitosana, um copolímero de glicosamina e $\mathrm{N}$-acetil glicosamina, é um polímero de caráter catiônico, biocompatível e biodegradável. Suas inúmeras propriedades físico-químicas e biológicas fazem com que o polímero tenha potencial de uso em inúmeras aplicações biomédicas, especialmente na área de Engenharia Tecidual. A Engenharia Tecidual é um ramo das Ciências da Saúde que visa o desenvolvimento de estruturas biológicas substitutas que ajam restaurando, mantendo ou melhorando funções teciduais. Scaffolds, estruturas extensivamente estudadas pela Engenharia de Tecidos são biomateriais tridimensionais produzidos a partir de biopolímeros, funcionando como arcabouços para o crescimento e proliferação de células. Neste trabalho conduzimos a confecção de scaffolds cilíndricos à base de quitosana com diferentes concentrações de material plastificante com finalidade de aplicação na área de medicina cardiovascular. Para isso nos dedicamos à optimização de metodologia de confecção das estruturas a partir de protocolos já existentes na literatura. Os resultados preliminares, a partir de técnicas físicas de caracterização, permitiram comparar as diferentes estruturas produzidas bem como concluir quais estruturas se mostram mais promissoras.

Palavras-chave: quitosana, engenharia tecidual, scaffolds, caracterização.

Abstract: Chitosan, a copolymer of glucosamine and N-
acetyl glucosamine, is a polycationic, biocompatible
and biodegradable polymer. Its unique physicochemical
and biological properties have proved the polymer to be
of great potential in a range of biomedical applications,
especially in the Tissue Engineering field. Tissue
Engineering is a field of the Health Sciences concerned
with the development of substitute biological structures
that can therefore act restoring, preserving or
improving tissue functions. Scaffolds, structures that
have been extensively studied by the Tissue Engineering
field, are tridimensional structures produced from
biopolymers that work as a support to cells to grow and
differentiate. In this work we have conducted the
production of cylindrical structures from chitosan
powder with different concentrations of plasticizers
added to the chitosan-made solution with potential
applicability in the field of cardiovascular health.
Earliest results have allowed to compare the different structures produced as well as to state which structures reveal as more promising.

Keywords: chitosan, tissue engineering, scaffolds, characterization.

\section{Introdução}

Ao longo dos últimos anos, filas de espera para quem aguarda por doações de órgãos só tem aumentado. Segundo dados da ABTO, Associação Brasileira de Transplantes de Órgãos, o número de doadores efetivos no primeiro trimestre de 2016 sofreu declínio em todas modalidades de transplante, $7,1 \%$ menos transplantações que 2015 no mesmo período, exceto transplantações pulmonares que vêm se mantendo constantes [1]. Embora ciências da saúde em geral têm se preocupado bastante com a produção de materiais sintéticos e vêm mostrando avanços significativos na área, há ainda a constante batalha contra altos índices de rejeição dos materiais sintéticos por parte dos receptores. Ambos fatores têm comprometido bastante tanto o sistema público quanto o sistema privado de saúde brasileiro.

Em paralelo, porém não tão distante, avanços em ciências da saúde em geral têm sido desacelerados por aspectos éticos e burocráticos. A limitação do uso indiscriminável de animais em pesquisas, embora justificável e com forte embasamento ético, tem prejudicado avanços científicos especialmente na área das ciências da saúde.

A urgente necessidade por órgãos e tecidos de modo a resolver a escassez de doadores efetivos e problemas de rejeição de transplatações bem como a importância em se fazer respeitar protocolos éticos e aspectos burocráticos faz com que a Engenharia Tecidual surja como ciência necessária para as ciências da saúde. A Engenharia Tecidual faz uso de ciências fundamentais, física, biologia e química, em prol do desenvolvimento de tecidos artificiais substitutos. Em geral os tecidos substitutos são crescidos sobre substratos tridimensionais biodegradáveis. Esses substratos são conhecidos no meio científico como scaffolds [2,3]. A técnica de scaffolding consiste na escolha de um composto, a manipulação do mesmo em um formato que justifique a aplicação e testes de caracterização que confirmem a aplicabilidade [2-6].

Este trabalho tem como objetivo apresentar uma metodologia desenvolvida para criação de uma matriz 
que aja comoscaffold, bem como a criação e caracterização das estruturas em caráter inicial via técnicas físicas.

\section{Materiais e métodos}

Para preparação dos scaffolds utilizamos de quitosana em pó derivada de cascas de caranguejo (Sigma Aldrich, St. Louis, MO), seguindo os passos:

1. Preparação de solução de ácido acético $2 \%$ (V/V);

2. A partir do ácido acético preparado conduziu-se a preparação de uma solução de quitosana 5\% $(\mathrm{m} / \mathrm{V})$ através da diluição da quitosana em pó na solução de ácido acético;

3. Adicionou-se material plastificante (glicerol) à solução de quitosana produzida de forma a obter três grupos de amostras: $10 \%$ de glicerol adicionado (amostras CHI10\%GLY), 5\% de glicerol adicionado (amostras CHI5\%GLY) e sem glicerol adicionado (amostras CHI0\%GLY);

4. A solução preparada foi colocada em tubos de ensaio de plástico que possuem um bastão de vidro concêntrico, desenvolvido em função do propósito do trabalho. A solução é então congelada em nitrogênio líquido;

5. Após o congelamento, o tubo é então removido e o conjunto bastão mais a solução congelada é mergulhado em hidróxido de sódio $5 \mathrm{M}(\mathrm{NaOH}$ $5 \mathrm{M}$ ) de forma a neutralizar a solução;

6. Após a neutralização, o resultado são estruturas gelatinosas de forma cilíndrica vazadas (tubos ocos). As amostras são então secas via dois métodos diferentes de secagem: liofilização, ou secagem a frio por 24 horas, e forno, ou secagem a quente por 48 horas, produzindo assim dois grupos diferentes de amostras com diferentes concentrações de plastificante adicionados. Os passos seguidos para preparação das amostras é ilustrado na Figura 1.

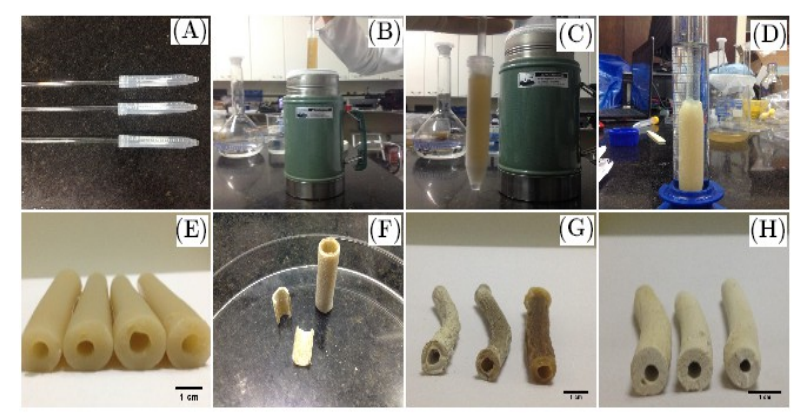

Figura 1: Produção dos scaffolds. Em (A) os tubos adaptados para confecção dos scaffolds. Em (B) a solução de quitosana congelada em nitrogênio líquido dando origem a uma estrutura congelada (C) que é removida do tubo e neutralizada em $\mathrm{NaOH}$ (D). Uma estrutura gelatinosa é então obtida (E), e levada para secagem, dando origem aos scaffolds $(\mathrm{F})$. Existem dois grupos de scaffolds que se diferem quanto ao método de secagem: secagem a quente $(\mathrm{G})$ e secagem a frio $(\mathrm{H})$.

Após a secagem das amostras podemos notar que existem dois grupos de amostras diferenciados em função do método de secagem empregado. Em cada grupo há ainda a produção de diferentes amostras preparadas com diferentes concentrações de glicerol adicionado à solução de quitosana inicial (CHI10\%GLY, CHI5\%GLY e CHI0\%GLY).

A última etapa consiste em caracterizar as amostras produzidas, isto é, obter parâmetros que nos permitam avaliar o potencial de aplicablidade das mesmas. Num primeiro instante avaliamos dois parâmetros de fundamental importância para a confecção de scaffolds: estabilidade, através do monitoramento das massas das estruturas ao longo de 15 dias, e rugosidade, através de técnicas de imagem, tais como Microscopia de Força Atômica (AFM) e Microscopia Eletrônica de Varredura (MEV).

\section{Resultados}

As amostras foram monitoradas ao longo de 15 dias de modo a observar se as estruturas produzidas possuíam estabilidade de massa, ou se eventuais perdas ou ganhos de massa continuam a acontecer ao longo to tempo. A Figura 2 ilustra a curva que descreve o comportamento em termos das massas das amostras secas a forno, enquanto que a Figura 3 ilustra a curva de comportamento das amostras secas a frio.

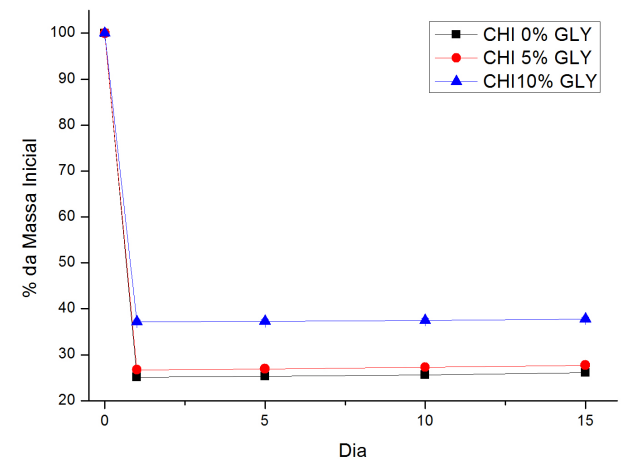

Figura 2: Curvas descrevendo o comportamento das amostras secas a quente sofrendo degradação de massa ao longo de 15 dias. 


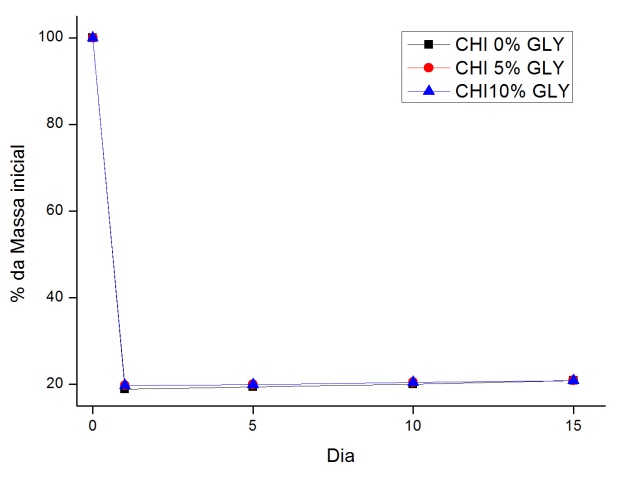

Figura 3: Curvas descrevendo o comportamento das amostras secas a frio sofrendo degradação de massa ao longo de 15 dias.

A topografia das amostras também foi monitorada de modo a observar padrões de rugosidade das estruturas produzidas. A rugosidade, assim como a estabilidade de massa das estruturas, é um padrão de extrema importância para a técnica de scaffolding uma vez que superfícies rugosas são capazes de promover maior adesão celular à estrutura produzida. Microscopia Eletrônica de Varredura a baixo vácuo, característica de amostras biológicas, foi conduzida apenas a caráter qualitativo de modo a observar se rugosidades estão presentes na superfície das amostras, o que é observado na Figura 4.

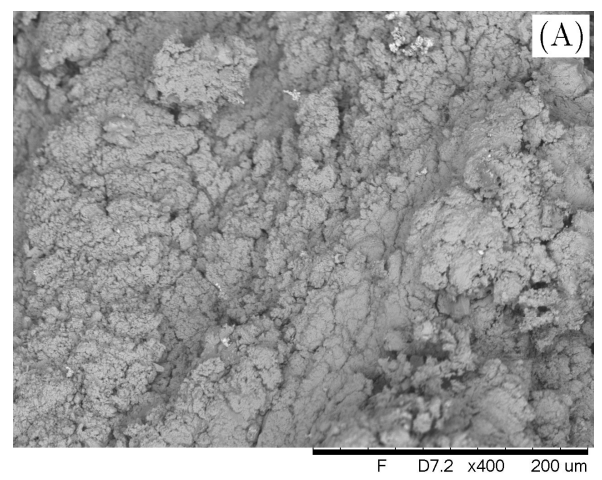

Figura 4: Caracterização de superfície de amostras CHI0\%GLY forno via MEV.

A Microscopia de Força Atômica em modo contato e não-contato foi utilizada em caráter qualitativo e quantitativo, de forma a observar a natureza rugosa das estruturas e confirmar a dimensão das rugosidades. $\mathrm{O}$ modo contato não pôde gerar imagens devido ao fato das amostras serem biológicas e ademais instáveis às condições do meio. O modo não-contato, mesmo enfrentando as mesmaas limitações do modo contato conseguiu varrer as amostras e gerar imagens das mais estáveis (CHI5\%GLY). As figuras 5 e 6 ilustram os resultados obtidos via AFM.

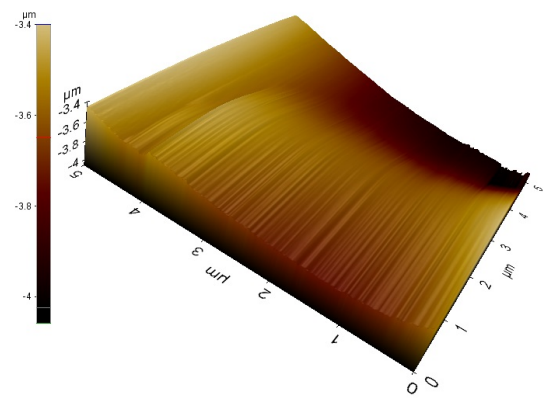

Figura 5: Reconstrução 3D de superfície de amostras CHI5\%GLY forno via AFM.

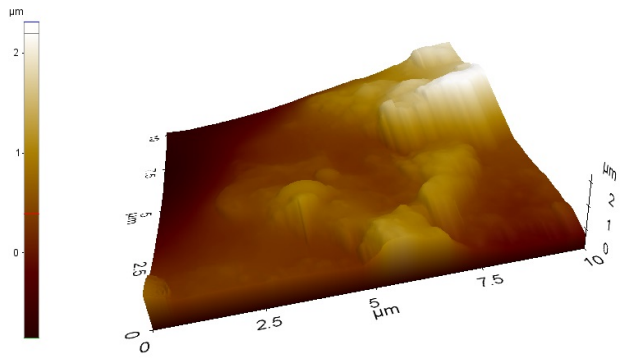

Figura 6: Reconstrução 3D de superfície de amostras CHI5\%GLY liofilizaçãoo via AFM.

\section{Discussão}

O monitoramento das massas das estruturas ao longo de um período de 15 dias permitiu verificar que as amostras perdem a maior porcentagem de suas massas no período de secagem, como era de se esperar, e depois se estabilizam. Destaca-se ainda que:

a. Para as amostras secas a forno, a perda de massa durante a secagem excedeu $60 \%$ da massa do período pós-neutralização. O glicerol age retendo a perda de água uma vez que amostras sem glicerol perderam cerca de $74 \%$ da massa durante a secagem enquanto que amostras com $10 \%$ de glicerol perderam cerca de $63 \%$ da massa durante o processo;

b. Para as amostras secas via liofilização, a perda de massa durante a secagem pareceu constante independentemente da concentração de glicerol. A perda de água é maior que para as estruturas secas a quente, e chega a aproximadamente $80 \%$ de redução das massas.

Independentemente do método de secagem, ao fim do intervalo de 15 dias todas as amostras já atingiram estabilidade de massa.

A técnica de produção de imagens via MEV, permitiu confirmar a presença de microvilosidades (rugas) na superfície das estruturas. A técnica foi utilizada apenas com fins qualitativos porém deve ser bastante utilizada em trabalhos futuros na determinação da dimensão dos poros presentes nas estruturas. 
Macroscopicamente, as estruturas secas a frio parecem visualmente lisas, sem rugosidade alguma enquanto que as estruturas secas a quente são rugosas até mesmo visualmente. A técnica de produção de imagens topográficas via AFM permitiu concluir que todas as estruturas são microrrugosas, com rugas de dimensões micrométricas. Tais resultados destacam ainda mais o potencial das estruturas produzidas.

Conclui-se portanto que os resultados preliminares aqui obtidos mostraram que foi possível o desenvolvimento e optimização de uma técnica de produção de scaffolds que sirvam para a área da medicina cardiovascular. As técnicas de caracterização realizadas até então permitiram confirmar certo potencial de aplicabilidade das estruturas e uso das estruturas, sinalizando para a continuidade do trabalho, desenvolvendo novos testes de caracterização tais como determinação de densidades das estruturas e absorção de líquido pelas estruturas em $\mathrm{pH}$ fisiológico, o que será abordado em trabalhos futuros.

\section{Agradecimentos}

Os autores agradecem às agências brasileiras FAPEMIG, CAPES e CNPq por suporte à pesquisa, e ao IX SEB - UFU por permitir a divulgação do trabalho.

\section{Referências}

[1] Registro Brasileiro de Transplantes (RBT). Associação Brasileira de Transplante de Órgãos [internet]. Veículo Oficial da Associação Brasileira de Transplante de Órgãos. Jan-Jun 2015. [cited 2016 Aug 03]. Available from:

http://www.abto.org.br/abtov03/Upload/file/RBT/20 15/rbt2015-1sem-lib2907.pdf.

[2] SHEN, Kai; QIAOLING Hu. "Layered chitosan conduits with controllable inner diameters." Materials Letters 65.10 (2011): 15031505.

[3] ZHU, Jixiang, et al. "Elastic chitosan conduits with multiple channels and well defined microstructure." International journal of biological macromolecules51.1 (2012): 105-112.

[4] HOLLISTER, Scott J. Porous scaffold design for tissue engineering. Nature materials, v. 4, n. 7, p. 518-524, 2005.

[5] CHAN, B. P.; LEONG, K. W. Scaffolding in tissue engineering: general approaches and tissue-specific considerations. European spine journal, v. 17, n. 4, p. 467-479, 2008.

[6]THOMSON, R. C. et al. Biodegradable polymer scaffolds to regenerate organs. In: Biopolymers Ii. Springer Berlin Heidelberg, 1995. p. 245-274. 